\title{
Perubahan Parameter Hidrolis Pada Drainase Primer Dengan Dinding Alami Akibat Sampah Padat
}

\author{
Changes in Hydraulic Parameters in Primary Drainage \\ With Natural Walls Due to Solid Waste
}

\author{
Endry Yoshua Todar ${ }^{1}$, Nomeritae ${ }^{2}$, dan I Made Kamiana ${ }^{3}$ \\ ${ }^{1}$ Jurusan Teknik Sipil, Fakultas Teknik, Universitas Palangka Raya, Jln. Yos Sudarso. Email : \\ endry.yt97@gmail.com \\ ${ }^{2}$ Jurusan Teknik Sipil, Fakultas Teknik, Universitas Palangka Raya, Jln. Yos Sudarso. Email : \\ nomeritae@jts.upr.ac.id \\ ${ }^{3}$ Jurusan Teknik Sipil, Fakultas Teknik, Universitas Palangka Raya, Jln. Yos Sudarso. Email : \\ kamianamade@eng.upr.ac.id
}

\begin{abstract}
Abstrak
Kota Palangka Raya adalah daerah yang sedang berkembang dimana adanya peningkatan jumlah penduduk. Hal tersebut dapat menimbulkan dampak lingkungan, salah satunya meningkatnya jumlah tumpukan sampah. Sampah ini harus dikelola dan dibuang pada tempat yang seharusnya, agar tidak membahayakan lingkungan dan melindungi investasi pembangunan. Misalnya sampah tersebut dibuang pada saluran drainase yang dapat menyebabkan kecepatan drainase dapat berkurang. Penelitian ini bertujuan untuk mengetahui perbandingan kecepatan analitis dan kecepatan terukur, kemudian mengetahui hubungan besar parameter hidrolis $\left(R_{\text {Analitis }}\right.$ dan $\left.R_{\text {Terukur }}\right)$ akibat sampah padat yang mengalir, dan mengetahui hubungan antara volume sampah padat terhadap kecepatan terukur. Mengenai perbandingan antara kecepatan terukur dan analitis secara umum terjadi overpredict. Untuk hubungan parameter hidrolis $\left(R_{\text {Terukur }}\right.$ dan $\left.R_{\text {Analitis }}\right)$ didapat nilai $R^{2}$ sebesar 0,9987, dengan hubungan persamaan regresi polynominal derajat 2 yaitu $y=0,0005 x^{2}-0,0137 x+0,0705$. Dan hubungan volume sampah padat dan kecepatan teukur didapat nilai $R^{2}$ sebesar 0,9968, dengan hubungan persamaan regresi polynomial derajat 2 yaitu $y=-0,0044 x^{2}-0,0257 x+0,3953$.
\end{abstract}

Kata Kunci: Parameter hidrolis; drainase primer; sampah padat

\begin{abstract}
The city of Palangka Raya is a developing area where the population is increasing. This can have an environmental impact, one of which is an increase in the amount of piles of garbage. This waste must be managed and disposed of in its proper place, so as not to harm the environment and protect development investments. For example, the garbage is dumped in a drainage channel which can reduce the speed of drainage. This study aims to determine the comparison of analytical speed and measured speed, then determine the large relationship of hydraulic parameters (analytical and measured $R$ ) due to solid waste flowing, and determine the relationship between the volume of solid waste and the measured velocity. Regarding the comparison between measured and analytical speed, it is generally overpredicted. For the relationship of hydraulic parameters (Measured $R$ and Analytical) the $R 2$ value is 0.9987 , with a degree 2 polynomial regression equation relationship, namely $y=$ $0.0005 x 2-0.0137 x+0.0705$. And the relationship between the volume of solid waste and the measured velocity, the $R 2$ value is 0.9968 , with the relationship between the polynomial regression equation degree 2 , namely $y=-$ $0.0044 x 2-0.0257 x+0.3953$.
\end{abstract}

Keywords: Hydraulic parameter; primary drainage; solid waste 


\section{PENDAHULUAN}

Kota Palangka Raya adalah daerah yang sedang berkembang dimana adanya peningkatan jumlah penduduk. Hal tersebut dapat menimbulkan dampak lingkungan, salah satunya meningkatnya jumlah tumpukan sampah. Sampah ini harus dikelola dan dibuang pada tempat yang seharusnya, agar tidak membahayakan lingkungan dan melindungi investasi pembangunan. Misalnya sampah tersebut dibuang pada saluran drainase yang dapat menyebabkan penyebab genangan. Drainase berfungsi untuk mengurangi atau membuang kelebihan air dari suatu kawasan atau lahan, sehingga lahan dapat difungsikan secara optimal sesuai dengan kepentingan dalam tata ruang, namun dengan adanya sampah padat (Solid Waste) pada saluran drainase membuat kapasitas dan kecepatan drainase dapat berkurang. Penelitian ini bertujuan untuk mengetahui perbandingan kecepatan analitis dan kecepatan terukur, kemudian mengetahui hubungan besar parameter hidrolis $\left(\mathrm{R}_{\text {Analitis }}\right.$ dan $\left.\mathrm{R}_{\text {Terukur }}\right)$ akibat sampah padat yang mengalir, dan mengetahui hubungan antara volume sampah padat terhadap kecepatan terukur.

\section{TINJAUAN PUSTAKA \\ Drainase}

Drainase mempunyai arti menguras, membuang, atau mengalirkan air. Secara umum, drainase didefinisikan sebagai serangkaian bangunan air yang berfungsi untuk mengurangi dan/atau membuang kelebihan air dari suatu kawasan atau lahan (Suripin 2004). Drainase secara umum didefinisikan sebagai ilmu pengatahuan yang memepelajari usaha untuk mengalirkan air yang berlebihan dalam suatu konteks pemanfaatan tertentu. Drainase perkotaan adalah ilmu yang diterapkan mengkhususkan pengkajian pada kawasan perkotaan yang erat kaitannya dengan kondisi lingkungan sosial yang ada di kawasan kota (H.A. Halim Hasmar,2011).

\section{Sampah}

Berdasarkan SK SNI 19-2454 (2002:1), Sampah merupakan sampah padat yang terdiri dari zat organik dan anorganik yang dianggap tidak berguna lagi dan terus dikelola agar tidak membahayakan lingkungan dan juga melindungi investasi tiap pembangunan. Ada juga pengertian sampah menurut Undang-Undang No.18 Tahun 2008 tentang Pengelolaan Sampah menyatakan bahwa sampah adalah sebagai sisa kegiatan sehari-hari manusia dan dari proses alam yang berbentuk padat.

\section{Pengukuran Kecepatan Aliran}

Pengukuran kecepatan aliran ini terdiri dari 2 macam metode, yaitu (Triadmodjo, 2008):

a. Metode Apung atau Pelampung

Pelampung bergerak terbawa oleh arus dan kecepatan arus didapat dari jarak tempuh dibagi dengan waktu tempuh. Ada tiga macam pelampung yang digunakan yaitu pelampung permukaan, pelampung dengan kaleng, dan pelampung dengan batang. Pelampung dengan tipe pertama mengukur kecepatan aliran pada permukaan, sedangkan tipe kedua dan ketiga untuk mengukur kecepatan rerata pada vertikal. Triadmodjo, 2008).

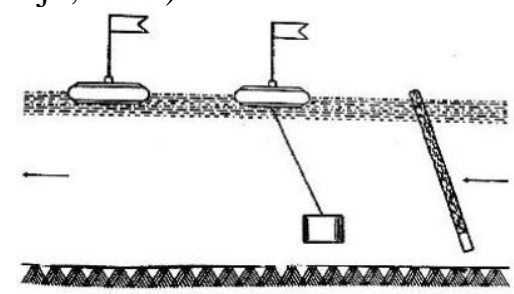

Gambar 1. Macam - macam pelampung untuk mengukur kecepatan aliran

\section{b. Current Meter}

Pengukuran kecepatan air dilakukan secara langsung dengan menggunakan current meter. Ada dua tipe alat ukur yaitu tipe mangkok (Pricecup Current Meter) dan baling-baling (Propeller Current Meter), Seperti ditunjukan dalam gambar 2. Hubungan antara jumlah putaran per detik, n, dan kecepatan aliran (v), mempunyai bentuk persamaan linier berikut:

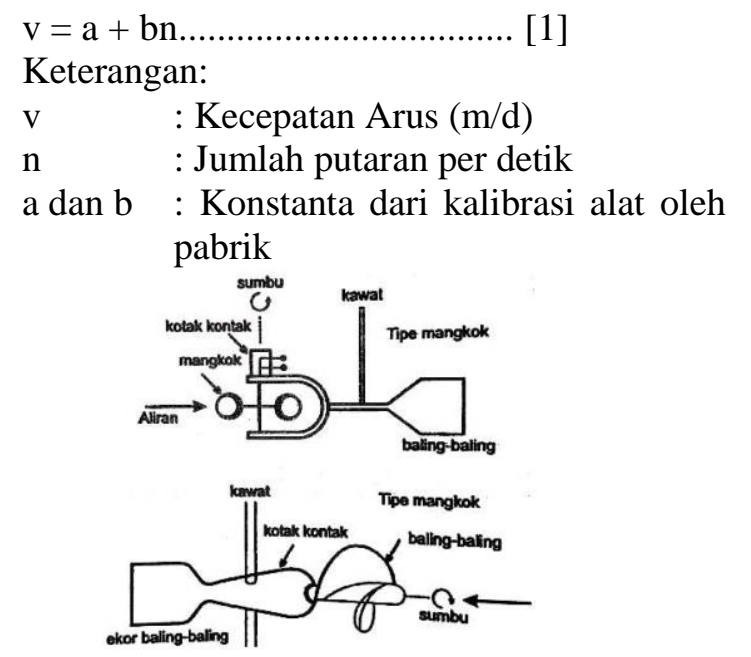

Gambar 2. Bentuk Current Meter Tipe Mangkok dan Baling-baling

Pengukuran dilakukan di beberapa titik pada vertical. 
Tabel 1. Titik Ukur Current Meter

\begin{tabular}{ccc}
\hline Pengukuran & $\begin{array}{c}\text { Kedalaman } \\
(\mathrm{m})\end{array}$ & Titik Ukur \\
\hline 1 Titik & $0,0-0,6$ & $0,6 \mathrm{~d}$ \\
\hline 2 Titik & $0,6-3,0$ & $0,2 \mathrm{~d}$ dan $0,8 \mathrm{~d}$ \\
\hline 3 Titik & $3,0-6,0$ & $0,2 \mathrm{~d} ; 0,6 \mathrm{~d}$ dan $0,8 \mathrm{~d}$ \\
\hline
\end{tabular}

\section{Sumber: Bambang Triatmodjo}

\section{Perhitungan Kecepatan Aliran}

Perhitungan kecepatan ini menggunakan rumus manning. Rumus dalam menghitung kecepatan tersebut dapat dilihat pada persamaan berikut.

$\mathrm{V}=$

$\frac{1}{n} \times R^{2 / 3} \times S^{1 / 2}$

[2]

Keterangan:

$\mathrm{n}$ : Koefisien kekasaran manning

$\mathrm{R}$ : Jari- jari Hidrolis

$\mathrm{S}$ : Kemiringan dasar saluran

Nilai R (Jari-jari Hidrolis) dihitung dengan menggunakan persamaan:

$\mathrm{R}=\frac{\mathrm{A}}{\mathrm{P}}$

Keterangan:

$\mathrm{R}$ : Jari-jari Hidrolis

A : Luas Penampang Basah

$\mathrm{P}$ : Keliling Penampang Basah

\section{METODE}

Penelitian ini dilakukan bertujuan untuk mengetahui pengaruh adanya sampah padat pada saluran drainase primer dengan dinding alami. Pada penelitian ini sampah padat yang digunakan berupa sampah padat dengan berbagai jenis yang sesuai keadaan lingkungan sekitar di lokasi penelitian. Langkah-langkah penelitian ini dimulai dari pengumpulan data seperti, pengukuran dimensi profil saluran drainase primer, pengukuran kecepatan aliran, dan pengukuran volume sampah padat Setelah melakukan pengumpulan data, kemudian menganalisa data sesuai dengan parameter yang akan digunakan.

\section{Pengukuran Penampang Saluran}

Hal pertama yang harus dilakukan adalah mengukur setiap dimensi saluran, seperti lebar saluran, kedalaman, panjang saluran serta kemiringan dinding saluran. Data-data tersebut digunakan untuk menghitung luas penampang.

\section{Pengukuran Volume Ssampah Padat}

Sampah padat yang dimaksudkan dalam penelitian ini adalah suatu sampah yang menumpuk menjadi satu bagian dari berbagai sumber, sehingga sampah tersebut terlihat padat. Pengukuran volume sampah padat ini dilakukan dengan membuat balok yang bahannya dari karton jepang, kemudian sampah padat dimasukan kedalam balok tersebut diukur sesuai dengan volume yang sudah ditentukan. Tumpukan sampah padat ini direncanakan sebanyak 5 sampel dengan volume yang berbeda.

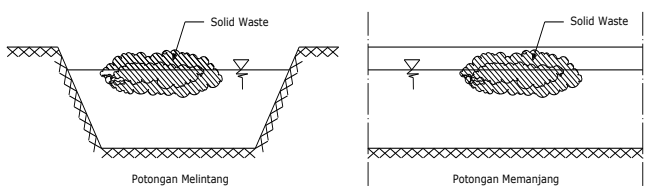

Gambar 3 Sketsa Sampah Padat Pada Drainase Primer

\begin{tabular}{|c|c|c|c|c|c|}
\hline & \\
\hline Volume & (m3) & (m3) & (m3) & (m3) & $(\mathrm{kg})$ \\
\hline V1 & 0,500 & 0,500 & 0,100 & 0,025 & 1,63 \\
\hline $\mathrm{V} 2$ & 0,500 & 0,500 & 0,200 & 0,050 & 2,37 \\
\hline V3 & 0,500 & 0,500 & 0,300 & 0,075 & 4,00 \\
\hline V4 & 0,500 & 0,500 & 0,400 & 0,100 & 6,00 \\
\hline V5 & 0,500 & 0,500 & 0,500 & 0,125 & 7,63 \\
\hline
\end{tabular}

Tabel 2. Sampel Volume Sampah Padat

\section{Pengukuran Kecepatan Aliran}

Pengukuran kecepatan aliran ini dilakukan dengan menggunakan current meter tipe baling-baling (Propeller Current Meter). Pengukuran ini dilakukan di beberapa titik pada bidang vertikal, melintang dan memanjang aliran.

a. Bidang Vertikal

Bidang vertikal ini dilakukan pada titik tertentu, dapat dilihat pada tabel 1 .

b. Bidang Melintang

Pengukuran kecepatan pada penampang melintang ini dilakukan dengan membagi penampang saluran menjadi beberapa rai

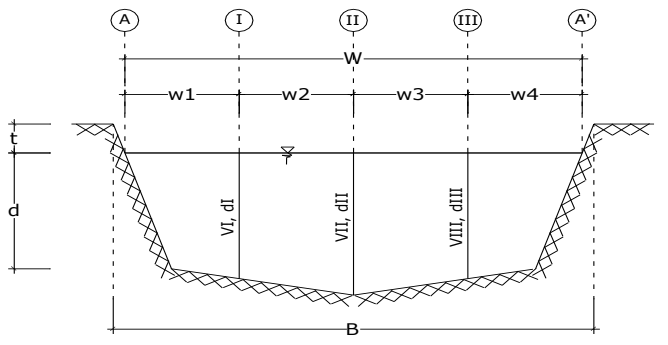

Gambar 4. Sketsa Titik Ukur Bidang Melintang

Proteksi/Desember 2021 Volume 3 No. 2 
Keterangan:

$\begin{array}{ll}\mathrm{t} & \text { : Tinggi jagaan }(\mathrm{m}) \\ \mathrm{d} & : \text { Kedalaman aliran }(\mathrm{m}) \\ \mathrm{B} & : \text { Lebar Penampang Saluran }(\mathrm{m}) \\ \mathrm{W} & \text { : Lebar Aliran }(\mathrm{m}) \\ \mathrm{W}_{1,2, . . \mathrm{dst}} & : \text { Lebar antar rai }(\mathrm{m})\end{array}$

c. Bidang Memajang

Pada penampang memanjang saluran ini akan dibagi menjadi 3 segmen dengan jarak $4 \mathrm{~m} / \mathrm{segmen}$, sehingga total panjang saluran yang diukur adalah 12 m. Posisi alat pengukur kecepatan (Current Meter) berada dititik hulu dan hilir dari segmen tersebut dan dilakukan pengukuran secara bersamaan. Pengukuran kecepatan ini dimulai pada saat sampah telah bergerak dan menyentuh titik hulu segmen. Untuk sketsanya dapat dilihat pada gambar 5 .

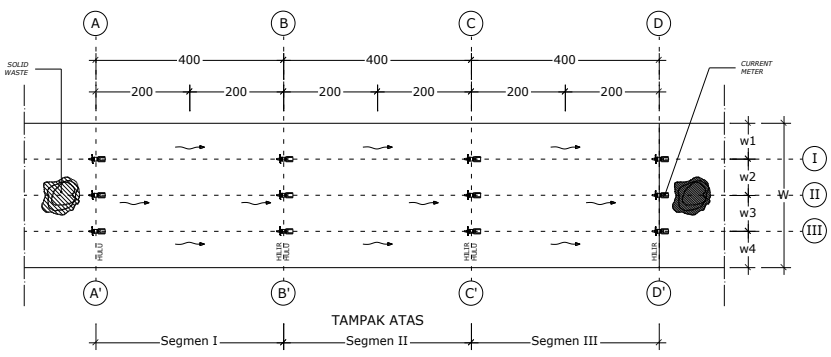

Gambar 5. Sketsa Titik Ukur Bidang Memanjang

Keterangan:

W : Lebar Aliran (m)

$\mathrm{W}_{1,2 . \mathrm{dst}} \quad$ : Lebar Antar Rai (m)

\section{Analisis Data}

a. Luas Penampang Saluran

Penampang saluran pada lokasi penelitian tersebut berbentuk trapesium. umumnya saluran ini terbuat dari tanah akan tetapi tidak menutup kemungkinan dibuat dari pasangan batu dan beton.

b. Perhitungan Kecepatan Analitis

Perhitungan kecepatan secara analitis pada penelitian ini, adalah kecepatan yang dianalisis menggunakan rumus Manning, dapat dilihat pada persamaan 2 dengan data-data yang didapat langsung dari lokasi penelitian.

c. Perbandingan Kecepatan Terukur dan

Kecepatan Analitis

Kecepatan terukur pada penelitian ini adalah kecepatan aliran yang diukur dengan menggunakan current meter yang tidak termasuk sampah padat, sedangkan kecepatan analitis pada penelitian ini didapat dari hasil perhitungan dengan menggunakan rumus Manning pada persamaan 2. Data kecepatan terukur dan kecepatan analitis ini dibuat dan dianalisis untuk melihat simpangan antara kecepatan terukur dan kecepatan analitis.

d. Hubungan Besar Jari-jari Hidrolis ( $\mathrm{R}_{\text {Analitis }}$ dan $\mathrm{R}_{\text {Terukur }}$ )

Pada jari-jari hidrolis $\mathrm{R}_{\text {Aanaltis }}$ dapat digunakan rumus persamaan 3 , dimana datanya hanya memerlukan nilai luas penampang basah (A) dan keliling penampang basah $(\mathrm{P})$. Sedangkan untuk jarijari hidrolis $\mathrm{R}_{\text {Terukur menggunakan rumus }}$ persamaan 4. Karena data $\mathrm{R}_{\text {Terukur }}$ mengguanakan kecepatan terukur $\left(\mathrm{V}_{\text {Terukur }}\right)$ yang sudah didapat menggunakan current meter, sehingga rumus untuk menghitung $\mathrm{R}_{\text {Terukur }}$ sebagai berikut:

$\mathrm{R}=\left(\frac{\mathrm{vxn}}{\mathrm{S} / 2}\right)^{3 / 2}$

Keterangan:

$\mathrm{R}$ : Jari-jari Hidrolis

$\mathrm{v}:$ Kecepatan terukur

$\mathrm{n}$ : koefisien manning

$\mathrm{s}:$ kemiringan dasar saluran

e. Hubungan Kecepatan Terukur dan Sampah Padat

Hubungan volume sampah padat dan kecepatan terukur pada penelitian ini adalah hubungan antara volume sampah padat dengan 5 sampel yang berbeda, dan kecepatan aliran yang diukur dengan menggunakan current meter di saluran drainase primer. Dari data tersebut dibuat grafik hubungan untuk melihat nilai kecepatan aliran terukur yang di pengaruhi oleh sampah padat dengan volume sampel yang berbeda.

\section{HASIL DAN PEMBAHASAN}

\section{Luas Penampang Saluran}

Dari data pengukuran didapat luas dan keliling tiap bidang sebagai berikut:

Tabel 3. Hasil Perhitungan Luas dan Keliling Penampang

\begin{tabular}{ccc}
\hline Bidang & $\begin{array}{c}\text { Luas (A) } \\
(\mathrm{m})\end{array}$ & $\begin{array}{c}\text { Keliling (P) } \\
(\mathrm{m})\end{array}$ \\
\hline A-A $^{\prime}$ & 0,350 & 8,013 \\
\hline B-B $^{\prime}$ & 0,403 & 7,024 \\
\hline C-C $^{\prime}$ & 0,450 & 7,229 \\
\hline
\end{tabular}




\begin{tabular}{ccc}
\hline D-D' & 0,486 & 7,236 \\
\hline Sumber: Hasil Perhitungan
\end{tabular}

\section{Perhitungan Kecepatan Analitis}

Hasil perhitungan kecepatan analitis dengan menggunakan persamaan 2 , sebagai berikut.

$$
\begin{aligned}
& \mathrm{v}_{\mathrm{A}}=0,401 \mathrm{~m} / \mathrm{s} \\
& \mathrm{v}_{\mathrm{B}}=0,322 \mathrm{~m} / \mathrm{s} \\
& \mathrm{v}_{\mathrm{C}}=0,459 \mathrm{~m} / \mathrm{s} \\
& \mathrm{v}_{\mathrm{D}}=0,424 \mathrm{~m} / \mathrm{s}
\end{aligned}
$$

Tabel 4. Hasil Pengukuran Kecepatan Terukur

\begin{tabular}{ccccc}
\hline \multirow{2}{*}{$\begin{array}{c}\text { Kode } \\
\text { Sampah } \\
\text { Padat }\end{array}$} & Segmen & \multicolumn{3}{c}{ Kecepatan (v) } \\
\cline { 2 - 4 } & & Hulu & Hilir & Rata-rata \\
\hline \multirow{2}{*}{ V0 } & & $(\mathrm{m} / \mathrm{s})$ & $(\mathrm{m} / \mathrm{s})$ & $(\mathrm{m} / \mathrm{s})$ \\
\cline { 2 - 4 } & I & 0,369 & 0,339 & \\
\cline { 2 - 4 } 0,359 \\
\cline { 2 - 4 } & II & 0,376 & 0,335 & \\
\hline
\end{tabular}

\section{Perbandingan Kecepatan Terukur dan Kecepatan Analitis}

Kecepatan Terukur yang dimaksud adalah kecepatan yang diukur dengan menggunakan alat yang tidak dipengaruhi oleh sampah padat.

Tabel 5. Perbanding Kecepatan Teruku dan Kecepatan Analitis

\begin{tabular}{cccc}
\hline Bidang & Analitis & Terukur & Keterangan \\
\hline A-A' & 0,401 & 0,369 & Overpredict \\
\hline B-B' & 0,322 & 0,358 & Underpredict \\
\hline C-C' & 0,459 & 0,354 & Overpredict \\
\hline D-D' & 0,424 & 0,362 & Overpredict \\
\hline Rata-rata & 0,402 & 0,361 & Overpredict \\
\hline
\end{tabular}

Hasil pengukuran nilai kecepatan terukur adalah sebagai berikut:

Sumber: Hasil Pengukuran

Dari data-data kecepatan terukur dan kecepatan analitis yang sudah didapat, dibuat perbandingan untuk melihat simpangan antara kedua kecepatan tersebut.

Sumber: Hasil Rekapitulasi

\section{Hubungan Besar Jari-jari Hidrolis (RAnalitis dan $\mathbf{R}_{\text {Terukur) }}$}

Jari-jari hidrolis yang analitis didapat dari persamaan 3. Sehingga didapat hasilnya sebagai

\begin{tabular}{|c|c|c|c|c|c|c|}
\hline \multirow[t]{2}{*}{ Segmen } & \multirow{2}{*}{$\begin{array}{c}\mathrm{R}_{\text {Analitis }} \\
\text { (m) }\end{array}$} & \multicolumn{5}{|c|}{$\begin{array}{c}\mathrm{R}_{\text {Terukur }} \\
\text { (m) }\end{array}$} \\
\hline & & V1 & $\mathrm{V} 2$ & V3 & V4 & V5 \\
\hline A-A' & 0,044 & 0,036 & 0,025 & 0,018 & 0,009 & 0,004 \\
\hline B-B' & 0,057 & 0,056 & 0,047 & 0,033 & 0,019 & 0,005 \\
\hline C-C' & 0,062 & 0,037 & 0,030 & 0,021 & 0,011 & 0,008 \\
\hline D-D' & 0,067 & 0,048 & 0,035 & 0,024 & 0,013 & 0,007 \\
\hline Rata-rata & 0,058 & 0,044 & 0,034 & 0,024 & 0,013 & 0,006 \\
\hline $\begin{array}{l}\text { Sedangl } \\
\text { menggu } \\
\text { sebagai }\end{array}$ & kan & $\mathrm{uk}$ & $\begin{array}{l}\text { ri-jari } \\
n \\
n\end{array}$ & $\begin{array}{l}\text { hic } \\
\text { Dan }\end{array}$ & olis & $\begin{array}{r}\text { teruku } \\
\text { hasi }\end{array}$ \\
\hline
\end{tabular}
berikut:

$\begin{array}{ll}\mathrm{R}_{\mathrm{A}} & =0,044 \mathrm{~m} \\ \mathrm{R}_{\mathrm{B}} & =0,057 \mathrm{~m} \\ \mathrm{R}_{\mathrm{C}} & =0,062 \mathrm{~m}\end{array}$

$$
\mathrm{R}_{\mathrm{D}} \quad=0,067 \mathrm{~m}
$$

Tabel 6. Hasil Rekapitulasi Perhitungan Jari-jari Hidrolis Terukur

\section{Sumber: Hasil Perhitungan}

Dari data-data yang sudah didapat, dibuat grafik hubungan antar jari-jari hidrolis terukur dan analitis tersebut



Gambar 6. Hubungan Jari-jari Hidrolis Terukur dan Analitis

\section{Hubungan Kecepatan Terukur dan Sampah Padat}

Volume sampah yang digunakan dalam grafik hubungan dengan kecepatan terukur ini terdapat 5 sampel yang dapat dilihat pada lampiran. Kecepatan terukur yang didapat dari hasil pengukuran diambil rata-rata setiap potongannya, dapat dilihat pada tabel berikut. 
Tabel 7. Hasil Pengukuran Kecepatan Terukur

\begin{tabular}{ccccccc}
\hline \multirow{2}{*}{ Potongan } & \multicolumn{7}{c}{ Kecepatan $(\mathrm{m} / \mathrm{s})$} \\
\cline { 2 - 7 } & $\mathrm{V} 0$ & $\mathrm{~V} 1$ & $\mathrm{~V} 2$ & $\mathrm{~V} 3$ & $\mathrm{~V} 4$ & V5 \\
\hline A-A' & 0,369 & 0,349 & 0,278 & 0,224 & 0,142 & 0,081 \\
\hline B-B' $^{\prime}$ & 0,357 & 0,318 & 0,284 & 0,225 & 0,157 & 0,086 \\
\hline C-C' $^{\prime}$ & 0,354 & 0,325 & 0,284 & 0,222 & 0,142 & 0,090 \\
\hline D-D' & 0,362 & 0,339 & 0,274 & 0,217 & 0,146 & 0,093 \\
\hline Rata-rata & 0,361 & 0,333 & 0,280 & 0,222 & 0,147 & 0,087 \\
\hline
\end{tabular}

Sumber: Hasil Pengukuran

Dari data volume sampah padat (tabel 2) dan ratarata kecepatan terukur tersebut, dibuat grafik hubungan. Grafik hubungan dari kedua data tersebut dapat dilihat pada gambar berikut.

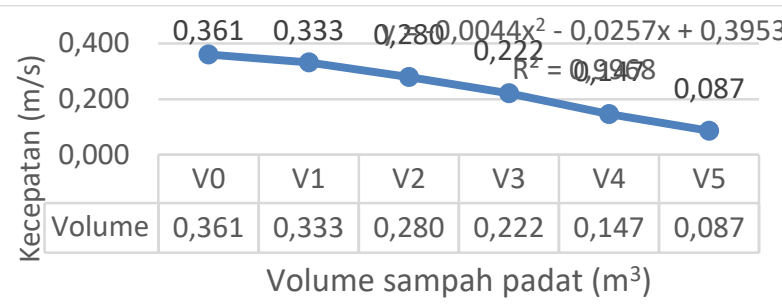

Gambar 7. Hubungan Kecepatan Terukur dan Sampah Padat

\section{SIMPULAN}

Dari hasil dan perhitungan pengaruh sampah padat (solid waste) pada saluran drainase primer, didapatkan kesimpulan sebagai berikut:

1. Perbandingan antara kecepatan analitis terhadap kecepatan terukur secara umum terjadi overpredict pada semua kecepatan potongan melintang terkecuali di potongan B-B'. Namun secara rata-rata terjadi overpredict kecepatan analitis terhadap kecepatan terukur.

2. Hubungan besar jari-jari hidrolis $\left(\mathrm{R}_{\text {Analitis }}\right.$ dan $R_{\text {Terukur }}$ ) pada saluran drainase primer dengan dinding alami diketahui bahwa volume sampah mempengauhi jari-jari hidrolis secara siginifikan yang ditunjukkan dengan $\mathrm{R}^{2}$ sebesar 0,9987. Hubungan antara volume sampah (x) dan jari-jari hidrolis (y) dijelaskan dalam hubungan persamaan regresi polynomial derajat 2 dengan persamaan $\mathrm{y}=0,0005 \mathrm{x}^{2}$ $0,0137 x+0,0705$.

3. Diketahui terdapat terdapat hubungan yang siginifikan antara volume sampah dan kecepatan terukur yang ditunjukkan dengan nilai $\mathrm{R}^{2}$ sebesar 0,9968 . Hubungan antara volume sampah (x) dan kecepatan terukur (y) dijelaskan dalam hubungan persamaan regresi polynomial derajat 2 dengan persamaan $y=-0,0044 x^{2}-0,0257 x$ $+0,3953$. Sehingga didapat kesimpulan dari penelitian ini yaitu semakin besar volume sampah padat, kecepatan aliran semakin kecil.

\section{REFERENSI}

Anonim, 1991. "Tata Cara Pengelolaan Teknik Sampah Perkotaan". SNI. 19-2454- 1991.

Anonim, 2020. “Badan Pusat Statistik”. Palangka Raya.

Aprilia, E. 2014. "Evaluasi dan Perencanaan Saluran Drainase Dengan Sistem Drainase Permukaan Pada Kawasan Jalan Temanggung Tilung Kota Palangka Raya”. Fakultas Teknik. Universitas Palangka Raya: Palangka Raya.

Armanda, Y. 2020. "Kajian Saluran Drainase Di Daerah Jalan Seth Adji Kota Palangka Raya (Zona B)". Fakultas Teknik. Universitas Palangka Raya: Palangka Raya.

Chow, V. T, 1989. "Hidrolika Saluran Terbuka". Penerbit Erlangga, Jakarta.

Direktorat Perguruan Tinggi Swasta. 1978. "Drainase Perkotaan". Penerbit Gunadarma, Jakarta.

Darmanto, 1990, "Drainase Perkotaan", Seminar Sehari Himpunan Mahasiswa Teknik Sipil Universitas Muhammadiyah Malang.

Hadiwiyoto, S. 1983. "Penanganan dan Pemanfaatan Sampah". Yayasan Idayu, Jakarta.

Hasmar, H. 2012. "Drainase Terapan”. UII Press, Yogyakarta.

Hodges, Laurent. 1976. "Environmental Pollution. 2nd edition". Hold McDougal.

Kamiana, I. M. 2011. "Teknik Perhitungan Debit Rencana Bangunan Air". Graha Ilmu, Yogyakarta.

Mubarak, Wahid Iqbal dan Nurul C. 2009. "Ilmu Kesehatan Masyarakat: Teori dan Aplikasi. Salemba Medika, Jakarta.

Soemarto, C. D. 1999. "Hidrologi Teknik". Penerbit Erlangga, Jakarta.

Suripin. 2004. "Sistem Drainase Perkotaan yang Berkelanjutan". Andi Offset, Yogyakarta.

Tchobanoglous, G.H., Theissen, H., Vigil, S.A. 1993. "Integrated Solid Waste Management". McGraw Hill, New York.

Triatmodjo, B. 2008. "Hidrologi Terapan". Beta Offset, Yogyakarta.

Zulkifli, Arif. 2019. "Dasar-Dasar Ilmu Lingkungan". Penerbit Salemba Teknika. 